\title{
Bloodless Arterial Cannulation Technique
}

Sir,

Radial artery cannulation is often used for invasive arterial blood pressure monitoring and arterial blood gas analysis. It is a routine procedure in cardiac surgical theaters and Intensive Care Units. Common complications include radial artery spasm (20\%), hematoma (14\%), and hemorrhage $(0.5 \%){ }^{\left[{ }^{1]}\right.}$ However, many a times, this procedure involves blood spillage and soiling of drapes after successful cannulation. Further, in a haste to minimize this and establish the transducer connection quickly, there is always a potential risk of cannula dislodgement and needlestick injury to the health-care provider. According to the WHO, needlestick injuries nearly contribute to $95 \%$ of the HIV occupational seroconversions. ${ }^{[2]}$ To prevent this, the authors propose a simple modification of the radial arterial cannulation technique using Smiths medical Jelco ${ }^{\circledR}$ vascular access device. This technique is suitable for both direct and ultrasound-guided arterial cannulation.

Under all aseptic precautions, the desired site is prepped, cleaned, and infiltrated with local anesthesia. Prior to cannulation, the cap of the Jelco ${ }^{\circledR}$ is attached to the hub of cannula-stylet assembly [Figure 1a]. After puncturing the radial artery, free flow of arterial blood is seen inside the hub. This backflow of the blood is collected within the cap attached to the hub which prevents blood spillage. The cannula is then slowly advanced over the stylet by rotating movements [Figure 1b]. After this, radial artery with the cannula in situ is compressed proximally, while the stylet-cap assembly is withdrawn gently [Figure 1c]. Transducer assembly is then connected to the hub by the assistant.

The authors are of the opinion that such a modification will help to minimize the risk of blood spillage, soiling of drapes and operation theater floor, potential direct contact with the blood,

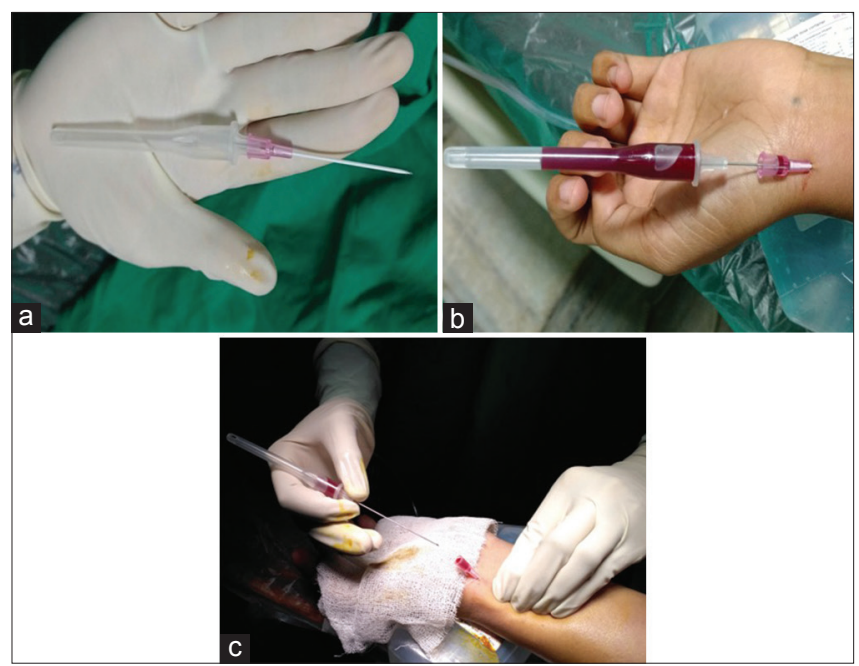

Figure 1: Arterial cannulation technique with (a) cap attached to the hub of Jelco ${ }^{\circledR}$; (b) blood being collected inside the cap and (c) clean site during fixation with proximal radial artery being compressed

and thereby blood-borne infections to the health-care personnel. In addition, the collected blood inside the cap can be used for biochemical analysis and investigations. This modification retains its cost-effectiveness in low-resource settings when compared to specialized intravenous safety catheters, namely BD arterial cannula with Floswitch ${ }^{\mathrm{TM}}$, BD Insyte ${ }^{\mathrm{TM}}$ Autoguard $^{\mathrm{TM}}$, BD Insyte $^{\mathrm{TM}}$ Autoguard ${ }^{\mathrm{TM}}$ Shielded IV Cannula, and Smiths medical Jelco $^{\circledR}$ ViaValve ${ }^{\circledR}$ safety IV catheters, which prevents backflow of blood using a one-way valve within its system. However, certain amount of skill and practice is required in this technical modification to maneuver the cannula into the arterial lumen without any manipulation of the stylet-cap assembly of Jelco ${ }^{\circledR}$. 


\section{Financial support and sponsorship}

Nil.

\section{Conflicts of interest}

There are no conflicts of interest.

Amruta Shringarpure, Pushkar Desai Department of Cardiac Anesthesiology, Seth GSMC and KEM Hospital, Mumbai, Maharashtra, India

Address for correspondence: Dr. Pushkar Desai, Department of Cardiac Anesthesiology, Seth GSMC and KEM Hospital, Mumbai, Maharashtra, India. E-mail: pushkarmdesai@gmail.com

\section{RefEREnCES}

1. Tiru B, Bloomstone JA, McGee WT. Radial artery cannulation: A review article. J Anesth Clin Res 2012;3:209.

2. WHO.int [Internet]. C2018 WHO. Available from: http://www.who.int/ occupational_health/topic/hcworkers/en/. [Last accessed 2018 Jul 6].
This is an open access journal, and articles are distributed under the terms of the Creative Commons Attribution-NonCommercial-ShareAlike 4.0 License, which allows others to remix, tweak, and build upon the work non-commercially, as long as appropriate credit is given and the new creations are licensed under the identical terms.

\begin{tabular}{|l|l|}
\hline \multicolumn{3}{|c|}{ Access this article online } \\
\hline Quick Response Code: & Website: \\
& www.ijccm.org \\
\cline { 2 - 2 } & \\
\hline
\end{tabular}

How to cite this article: Shringarpure A, Desai P. Bloodless arterial cannulation technique. Indian J Crit Care Med 2018;22:562-3.

C 2018 Indian Journal of Critical Care Medicine | Published by Wolters Kluwer - Medknow 